\title{
Novel treatment with percutaneus electrolysis in cervical whiplash syndrome
}

\author{
García Naranjo J.R. ${ }^{1,2}$ \\ ${ }^{1}$ Complejo Hospitalario Materno-Insular, Las Palmas, Spain \\ ${ }^{2}$ Centro de Rehabilitación Vecindario SL. Las Palmas, Spain \\ Rev Fisioter Invasiva 2019;2:70-71.
}

\section{Abstract}

\section{Keywords}

- whiplash syndrome

- percutaneous needle electrolysis

- enthesitis
Introduction and Aims Cervical whiplash syndrome (CWS) commonly occurs because of the rear impact of motor vehicle collisions, producing a forced passive extension of the neck, followed by a rapid flexion in the form of a whip. This violent flexion can lead to an enthesopathy of the levator scapulae muscle (LS). The aim of this study was to evaluate the effectiveness of the percutaneous needle electrolysis (PNE) technique on the enthesopathy of the LS after a CWS and to compare this with a conventional physical therapy protocol.

Material and Methods In a physical therapy center specialized in traffic accidents, we arranged to interview a sample of 100 voluntary patients, providing subjects with the inclusion-exclusion criteria and an informed consent form. Participants recruited to the study had their pain quantified using the visual analog scale (VAS) for pain, the validated neck pain questionnaire (NPQ), and an algometer. Two groups were created. One received the PNE technique and the other received the conventional physiotherapy protocol. Once treatments were completed, pain was quantified once again and the results were obtained.

Results The most important findings are highlighted, regarding the comparison of variables of pain quantification in both groups and regarding the cost per treatment session. Comparative of both groups for the VAS variable, before and after:

\begin{tabular}{|l|l|l|l|}
\hline Group & VAS pre & VAS post & \% Improvement \\
\hline Conventional physiotherapy & 6.7136 & 5.1211 & 31.3 \\
\hline PNE technique & 6.8664 & 5.0689 & 35.3 \\
\hline
\end{tabular}

Comparative of both groups with the algometry variable before and after:

\begin{tabular}{|l|l|l|l|}
\hline Group & Alg. pre & Alg. post & \% Improvement \\
\hline Conventional physiotherapy & 3.1778 & 4.1503 & 23.5 \\
\hline PNE technique & 2.059 & 3.4477 & 40.3 \\
\hline
\end{tabular}

Comparative of both groups for the NPQ before and after:

\begin{tabular}{|l|l|l|l|}
\hline Group & NPQ pre & NPQ post & \% Improvement \\
\hline Conventional physiotherapy & 79.025 & 68.0417 & $16.4 \%$ \\
\hline PNE technique & 73.52 & 61.894 & $18.8 \%$ \\
\hline
\end{tabular}

Copyright $\odot 2019$ by Thieme Revinter Publicações Ltda, Rio de Janeiro, Brazil 
Treatment cost for each group:

\begin{tabular}{|l|l|l|l|}
\hline Price per session & Group & Sessions & Treatment cost \\
\hline \multirow{2}{*}{$15.82 €$} & Conventional physiotherapy & 20 & $316,4 €$ \\
\cline { 2 - 4 } & PNE technique & 3 & $47,46 €$ \\
\hline
\end{tabular}

\section{Conclusions}

1. The conventional physiotherapy protocol used is effective for the reduction of pain in the SLC in the enthesopathy of the LS.

2. Treatment with the PNE technique is effective for the reduction of pain in the CWS for LS enthesopathy.

3. Physiotherapy treatment which includes the PNE technique is more effective in the algometry variable than treatment performed with conventional physiotherapy techniques by $16.8 \%$.

3. The PNE technique is superior to the protocol of conventional physiotherapy in the cost/effectiveness relationship by $85 \%$.

4. The PNE technique, without combining the same with any other physiotherapy technique, is effective for the reduction of pain in cases of enthesopathy. 